\title{
METODE AKUPRESUR SEDERHANA GUNA MENURUNKAN TINGKAT KELELAHAN DAN ANSIETAS PADA RELAWAN COVID 19 DI KABUPATEN MALANG
}

\author{
${ }^{1}$ Oda Debora, ${ }^{2}$ Sulistyono \\ Program Studi S-1 Keperawatan, STIKes Panti Waluya Malang \\ Jl. Yulius Usman no. 62 Malang, (0341) 369003 \\ e-mail: katarina29debora@gmail.com
}

\begin{abstract}
ABSTRAK
Saat ini Indonesia sedang berada di tengah Pandemi Covid 19, yang dalam penanganannya melibatkan banyak pihak dan salah satunya adalah relawan. Salah satu kelompok relawan di Kabupaten Malang adalah Balakarcana. Mereka membantu masyarakat daerah Poncokusumo dalam pertolongan pertama, membawa masyarakat yang sakit ke Puskesmas atau Klinik. Dalam masa pandemi, mereka tidak dilengkapi dengan sarana yang lengkap sehingga hanya bekerja dengan peralatan yang seadanya. Kondisi ini menimbulkan kekhawatiran tertular Covid 19. Selain pengetahuan dalam penanganan kesehatan masyarakat oleh relawan pada masa Covid 19, diperlukan bantuan lain guna menurunkan kelelahan dan ansietas mereka. Salah satu metode yang dapat diterapkan secara mandiri untuk menurunkan kelelahan dan ansietas adalah akupresur. Akupresur merupakan salah satu metode dari Cina yang sudah diterapkan dalam waktu lama untuk berbagai macam penyakit dan terbukti dapat menurunkan tingkat kecemasan. Kegiatan yang dilakukan adalah memberikan pengetahuan tentang pencegahan penularan Covid 19 dan penerapan metode akupresur kepada anggota relawan melalui kegiatan Focused Group Discussion dan workshop sederhana tentang topik tersebut. Kegiatan tersebut diikuti oleh 11 orang relawan. Relawan merasa bahwa kegiatan tersebut dapat membantu mereka dalam proses penanganan kesehatan masyarakat dan akupresur membantu mereka mengurangi kelelahan. Kegiatan serupa diharapkan dapat dilaksanakan agar penatalaksanaan kelelahan dan ansietas dapat dioptimalkan.
\end{abstract}

\section{Kata Kunci-kelelahan, ansietas, pandemi Covid 19, pre-hospital, relawan}

\begin{abstract}
Currently, Indonesia is in the midst of the Covid 19 Pandemic, which in its handling involves many parties and one of them is volunteers. One of the volunteer groups in Malang Regency is Balakarcana. They assist the community in the Poncokusumo area in first aid, bringing the sick to the Puskesmas or Clinic. During a pandemic, they are not equipped with complete facilities, so they only work with minimal equipment. This condition raises concerns about contracting Covid 19. In addition to knowledge in handling public health by volunteers during the Covid 19 period, other assistance is needed to reduce their fatigue and anxiety. One method that can be applied independently to reduce fatigue and anxiety is acupressure. Acupressure is a Chinese method that has been used for a long time for a wide variety of ailments and has been shown to reduce anxiety levels. The activities carried out were to provide knowledge about the prevention of Covid 19 transmission and the application of acupressure methods to volunteer members through Focused Group Discussions and simple workshops on the topic. This activity was attended by 11 volunteers. Volunteers feel that the activity can help them in the process of managing public health and acupressure helps them reduce fatigue. It is hoped that similar activities can be carried out so that the management of fatigue and anxiety can be optimized.
\end{abstract}

Key Words--- fatigue, anxiety, Covid 19 Pandemic, pre-hospital, volunteer

\section{PENDAHULUAN}

Awal tahun 2020 hingga saat ini, dunia masih menghadapi pandemi Covid 19. Pandemi ini juga dialami di daerah Jawa Timur, salah satunya di Kabupaten Malang. Jumlah penderita covid 19 pada bulan Agustus mencapai 521 penderita (Faruq, 2020). Jumlah penderita Covid
19 setiap hari juga mengalami peningkatan di Kabupaten Malang. Peningkatan jumlah penderita Covid 19 di Kabupaten Malang menimbulkan dampak pada proses pelayanan kesehatan di luar rumah sakit yang sebagian besar dilaksanakan oleh 
relawan. Relawan ada yang memiliki latar belakang medis, tetapi lebih banyak yang tidak memiliki latar belakang kesehatan. Perbedaan bekal ini membawa konsekuensi tersendiri bagi kegiatan pertolongan yang dilakukan. Perbedaan kemampuan yang mencolok adalah pengendalian infeksi yang saat ini diperlukan dalam kegiatan pencegahan penyebaran infeksi (Tan, 2020).

Secara geografis, Desa Pandansari terletak di lereng gunung Semeru dan berdekatan dengan Gunung Bromo. Karena letaknya yang berada di antara gunung berapi aktif, secara sukarela terbentuklah kelompok relawan yang diberi nama Balakarcana. Kelompok relawan ini tidak hanya berperan saat terjadi bencana, namun juga membantu memberikan bantuan kesehatan sesuai dengan kemampuan mereka kepada masyarakat yang membutuhkan. Kegiatan yang dilakukan antara lain membantu transportasi anggota masyarakat ke Puskesmas, mengantar korban kecelakaan ke rumah sakit terdekat atau ke Puskesmas meskipun dengan keterbatasan sarana prasarana yang mereka miliki.

Kegiatan Balakarcana memiliki tujuan yang baik, namun karena keterbatasan alat pelindung diri dan ketakutan yang muncul akibat pandemi Covid 19, tidak jarang relawan mengalami kecemasan akan tertular Covid 19. Kecemasan yang berkepanjangan akan memunculkan berbagai permasalahan fisik (Ballesio, Lombardo, Lucidi, \& Violani, 2020).

\section{METODE}

Program

kemitraan ini menggunakan metode penyuluhan kesehatan dan workshop sederhana. Subjek dalam program pengabdian masyarakat ini adalah relawan Balakarcana. Kegiatan ini dilaksanakan di desa Pandansari. Metode yang digunakan adalah penyuluhan dan workshop bersama tentang topik terkait. Pertemuan dilaksanakan sebanyak 3 kali dengan tema penyuluhan dan workshop yang disesuaikan dengan kebutuhan informasi yang diperlukan masyarakat.

\section{HASIL dan PEMBAHASAN}

Ketiga kegiatan penyuluhan dan workshop dilaksanakan di salah satu rumah warga yang memiliki halaman luas. Kegiatan ini dilaksanakan pada hari Sabtu dan dihadiri oleh 11 dan 13 orang relawan Balakarcana.

1. Kegiatan pertama adalah penyuluhan dan workshop tentang pemberian pertolongan pertama yang aman dilakukan pada masa pandemi. Kegiatan ini dihadiri oleh 11 orang relawan Balakarcana;

2. Kegiatan kedua adalah penyuluhan dan workshop tentang metode akupresur sederhana pada anggota relawan. Kegiatan ini dihadiri oleh 13 relawan Balakarcana;

3. Kegiatan ketiga adalah penyuluhan dan workshop tentang pertolongan pertama pada kejang demam anak serta pemberian kompres hangat yang dihadiri oleh 13 peserta.

Tabel 1. Alat dan Bahan Penyuluhan dan Workshop Metode Akupresur Sederhana Guna Menurunkan Tingkat Kelelahan Dan Ansietas Pada Relawan

\begin{tabular}{llc}
\hline No & Alat \& Bahan & n \\
\hline 1. & LCD & 1 \\
\hline 2. & Leaflet & 45 \\
\hline
\end{tabular}

Masa pandemi berdampak pada kehidupan sosial ekonomi seluruh lapisan masyarakat. Dampak tersebut tidak hanya dialami oleh masyarakat saja, tetapi juga oleh tenaga kesehatan yang bekerja di dalam dan luar rumah sakit. Ada banyak faktor yang berpengaruh terhadap kesehatan psikologis ini, diantaranya adalah informasi yang tidak benar, stigmatisasi 
oleh masyarakat, burnout atau kelelahan, dan Post Traumatic Stress Disorder (Sood, 2020). Sebuah penelitian di Turki menyebutkan bahwa pandemi Covid 19 ini berdampak hebat terhadap kondisi psikologis dari berbagai usia dan lapangan pekerjaan. Guna menurunkan dampak negatif psikologis tersebut, diperlukan tindakan nyata misalnya dengan pemberian edukasi agar berbagai kejadian negatif akibat pandemi dapat disaring oleh penerima informasi dan tidak menimbulkan kepanikan (Akat \& Karataş, 2020). Kegiatan pengabdian masyarakat ini mendukung hasil penelitian tersebut. Pengabdi telah memberikan informasi terkait cara penularan serta pencegahan penyebaran infeksi Covid 19 saat memberikan pertolongan kesehatan bagi orang lain yang membutuhkan.

Seperti hasil penelitian sebelumnya, tenaga kesehatan di luar rumah sakit juga mengalami kelehan dan ansietas akibat pandemi (Sood, 2020). Relawan merupakan salah satu tenaga pre-hospital yang membantu memberikan pelayanan kesehatan kepada masyarakat. Bantuan fisik sederhana yang dapat diterapkan guna mengurangi kelelahan dan kecemasan adalah dengan menerapkan stimulus pada titik akupuntur secara mandiri, misalnya dengan akupresur (Church \& Feinstein, 2017). Penelitian tersebut mendasari pemilihan kegiatan akupresur guna menurunkan kelelahan dan ansietas pada relawan. Beberapa titik akupresur yang dapat menurunkan kelelahan dan kecemasan disampaikan kepada peserta.

Dalam kegiatan tersebut juga dilaksanakan workshop sehingga peserta dapat langsung menerapkan secara langsung cara melakukan penekanan pada titik akupuntur untuk mendapatkan hasil yang diharapkan. Kegiatan workshop ini dilakukan agar kemampuan psikomotor peserta semakin terasah. Lubbers \& Rossman (2017) juga menyebutkan bahwa kegiatan simulasi dapat meningkatkan kepercayaan diri karena pernah melakukan suatu prosedur secara mandiri. Sehingga jika suatu saat diperlukan, mereka dapat melaksanakan suatu prosedur dengan benar (Lubbers \& Rossman, 2017).

Sebuah penelitian di Cina menyebutkan bahwa kasus Covid 19 juga ditemukan pada anak dan yang terkonfirmasi sejumlah 728 anak dengan rata-rata usia anak yang menderita Covid 19 adalah 7 tahun (Dong et al., 2020). Hal ini terkait dengan salah satu materi yang khusus diminta oleh relawan wanita, yaitu kejang demam meskipun kasus ini ini jarang ditemukan, saat didapatkan kondisi tersebut mereka merasa tidak mampu dan panik. Para ibu-ibu relawan mengatakan bahwa mereka belum pernah mendapatkan informasi tentang kejang demam. Biasanya mereka akan langsung membawa ke rumah sakit, tetapi dalam kondisi pandemi, mereka ragu untuk membawa anak yang kejang demam ke rumah sakit karena takut tertular covid 19.

Keluhan yang diungkapkan adalah ketidaktahuan dan menanyakan bagaimana cara tata laksananya. Pengabdi merespon dengan memberikan penjelasan tentang pertolongan pertama kejang demam serta cara melakukan kompres hangat. Beberapa penelitian menunjukkan bahwa metode kompres hangat dengan suhu yang mendekati suhu normal tubuh terbukti efektif dalam menurunkan hipertermia pada anak jika dibandingkan dengan tepid sponge (Karra, Anas, Hafid, \& Rahim, 2019). Hal ini lah yang mendasari kegiatan workshop pemberian kompres hangat dalam upaya menurunkan demam sebagai penyebab kejang pada anak.

Proses penyampaian materi sebaiknya disertai pemilihan media pembelajaran tepat agar capaian pembelajaran dapat tersampaikan. Selain itu, karakteristik penerima informasi juga harus diperhatikan agar mendapat 
hasil yang maksimal. (Vieira, Parsons, \& Byrd, 2018). Pengabdi menggunakan media LCD untuk menyampaikan PPT tentang topik yang disampaikan. Agar informasi yang diberikan tidak terlewat, pengabdi juga memberikan leaflet yang dapat dapat dibaca ulang dan disebarkan kepada orang lain yang membutuhkan oleh relawan dan.

\section{KESIMPULAN DAN SARAN}

Hasil dari program kemitraan ini adalah membantu para relawan Balakarcana dalam menurunkan kelelahan dan kecemasan mereka. Selain itu, relawan wanita dapat memberikan pertolongan pertama secara tepat kepada anak-anak yang mengalami kejang demam di rumah, tanpa perlu membawa ke rumah sakit.

\section{UCAPAN TERIMA KASIH} kepada:

Ucapan terima kasih diberikan

1. Ketua Yayasan Pendidikan Misericordia

2. Ketua STIKes Panti Waluya Malang

3. Ketua Balakarcana Kecamatan Poncokusumo Kabupaten Malang

4. Ketua LPPM STIKes Panti Waluya Malang

\section{DAFTAR PUSTAKA}

Akat, M., \& Karataş, K. (2020). Psychological Effects of COVID-19 Pandemic on Society and Its Reflections on Education. Electronic Turkish Studies, 15(4).

Ballesio, A., Lombardo, C., Lucidi, F., \& Violani, C. (2020). Caring for the carers: Advice for dealing with sleep problems of hospital staff during the COVID-19 outbreak. Journal of Sleep Research, e13096.

Church, D., \& Feinstein, D. (2017). The manual stimulation of acupuncture points in the treatment of post- traumatic stress disorder: A review of clinical emotional freedom techniques. Medical Acupuncture, 29(4), 194-205.

Dong, Y., Mo, X., Hu, Y., Qi, X., Jiang, F., Jiang, Z., \& Tong, S. (2020). Epidemiology of COVID-19 among children in China. Pediatrics, 145(6).

Faruq, Daviq Umar Al. (2020). 81\% Pasien Covid-19 di Kabupaten Malang telah Sembuh. Medcom.id. https://www.medcom.id/nasional/da erah/1bVjPP2b-81-pasien-covid-19di-kabupaten-malang-telah-sembuh

Karra, A. K. D., Anas, M. A., Hafid, M. A., \& Rahim, R. (2019). The Difference Between the Conventional Warm Compress and Tepid Sponge Technique Warm Compress in the Body Temperature Changes of Pediatric Patients with Typhoid Fever. Jurnal Ners, 14(3), 321-326.

Lubbers, J., \& Rossman, C. (2017). Satisfaction and self-confidence with nursing clinical simulation: Novice learners, medium-fidelity, and community settings. Nurse Education Today, 48, 140-144.

Sood, S. (2020). Psychological effects of the Coronavirus disease-2019 pandemic. Research \& Humanities in Medical Education, 7, 23-26.

Tan, L. F. (2020). Preventing the transmission of COVID-19 amongst healthcare workers. Journal of Hospital Infection, 105(2), 364365.

Vieira, C., Parsons, P., \& Byrd, V. (2018). Visual learning analytics of educational data: A systematic literature review and research 
agenda. Computers \& Education, 122, 119-135. 